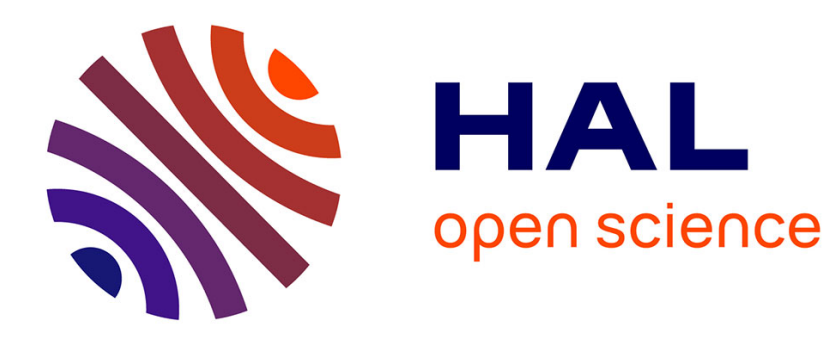

\title{
Layoff Costs and Efficiency with Asymmetric Information
}

\author{
Alain Delacroix, Etienne Wasmer
}

\section{To cite this version:}

Alain Delacroix, Etienne Wasmer. Layoff Costs and Efficiency with Asymmetric Information. 2009. hal-00972915

\section{HAL Id: hal-00972915 \\ https://hal-sciencespo.archives-ouvertes.fr/hal-00972915}

Preprint submitted on 3 Apr 2014

HAL is a multi-disciplinary open access archive for the deposit and dissemination of scientific research documents, whether they are published or not. The documents may come from teaching and research institutions in France or abroad, or from public or private research centers.
L'archive ouverte pluridisciplinaire HAL, est destinée au dépôt et à la diffusion de documents scientifiques de niveau recherche, publiés ou non, émanant des établissements d'enseignement et de recherche français ou étrangers, des laboratoires publics ou privés. 


\title{
Layoff Costs and Efficiency with Asymmetric Information
}

\author{
Alain Delacroix (UQAM) and Etienne Wasmer (Sciences-Po)
}

September 4, 2009

\begin{abstract}
Wage determination under asymmetric information generates inefficiencies due to excess turnover. Severance pay and layoff taxes can improve efficiency. We show that inefficient separations can even be fully removed with fixed separation taxes in the case where the relevant private information is exponentially distributed.
\end{abstract}

\section{Introduction}

In a world where employer-employee matches are characterized by private information, we know from Hall and Lazear (1984) that obtaining ex-post efficient trade is fraught with problems. The nature of the relationship creates a bilateral monopoly situation, and asymmetric information implies that some separations may be inefficient, i.e. the pair may have been better off staying together than separating. ${ }^{1}$ They investigate several wage determination schemes (predetermined wages, or giving monopoly power to one of the sides) and find that none completely solves the inherent inefficiencies. Nonetheless, they argue that simple wage contracts are often as desirable as more complicated contracts which have strong informational requirements.

In this note, we show how layoff taxes and severance payments can alleviate these inefficiencies in a simple setup. We find that:

- There are inefficient separations.

- Appropriately set, layoff taxes and severance pay may reduce and even suppress inefficient separations in the case of exponential distributions of private values.

- For other distributions, there is no set of fixed separation taxes that can remedy the inefficiency problem.

Our starting point is a wage setting mechanism emphasized by Shimer (2005) in the conclusion of his seminal paper on the volatility properties of Mortensen and Pissarides (1994) and Pissarides

\footnotetext{
${ }^{1}$ Myerson and Satterhwaite (1983) also find that, in their setup, ex-post efficiency cannot generally be obtained in bargaining situations with asymmetric information.
} 
(2000) setups. The wage setting suggested can be succinctly described as one where two negotiating entities have private information about the surplus they obtain from given wage offers. Nature decides which side makes the offer. The offering party then gets to make a take-it-or-leave-it offer, essentially maximizing its expected net surplus, taking into account that its offer must leave the other side better off than its outside option.

We look at one particular aspect of the firing cost literature. Firing costs have been analyzed along many dimensions. On the one hand, a branch of the literature takes the view $(i)$ that they contribute to the sclerotic labor markets observed in a number of continental European countries (Mortensen and Pissarides, 1999), and ( $i i$ ) that they carry high welfare costs due to misallocation of resources [Hopenhayn and Rogerson (1993), Alessandria and Delacroix (2008), Veracierto (2001)]. On the other hand, some other work (Alvarez and Veracierto, 2001; Fella, 2007; Wasmer, 2006) have outlined some potential benefits of firing costs when workers do not have a way to insure their idiosyncratic labor market risk. In this note, our interest lies in whether separation taxes which make separation more costly can reduce inefficiencies due to private information.

\section{The static model}

\subsection{Equilibrium}

A match is formed between two agents - a worker and a firm, who must negotiate a wage. If negotiations are successful, production generates output $h+\varepsilon$ where $h$ is known to both agents and $\varepsilon$ is a private value known by the firm only. The worker also has private valuation $\nu$ from the match. Each party has an exogenous outside option, $\mathcal{U}$ for the worker and $\mathcal{V}$ for the firm. Let $w$ be the negotiated wage. Thus payoffs from agreement are $(w+\nu, h+\varepsilon-w)$ to the worker and the firm respectively, while the inability to reach an agreement implies a separation and a set of payoffs $(\mathcal{U}, \mathcal{V})$.

Assumption 1. The private value $\varepsilon$ is drawn from a $\operatorname{cdf} F$ with support $\left[\varepsilon_{\min }, \varepsilon_{\max }\right]$. The private value $\nu$ is drawn from a cdf $G$, with support $\left[\nu_{\min }, \nu_{\max }\right]$. The distributions $F($.$) and G($.$) are$ common information. ${ }^{2}$ We make no restriction on $\varepsilon_{\max }$ and $\nu_{\max }$ which can be infinite, but exclude distributions for which the support has no lower bound (for reasons that will become clear later).

Assumption 2. Nature decides which side makes the offer: with probability $\beta(1-\beta)$, the firm (worker) makes a take-it-or-leave-it offer $w$.

(For simplicity of exposition, we only consider offers made by firms in the rest of the note, i.e. $\beta=1$. Worker offers can be treated symmetrically. All our results go through with the obvious adjustments. ${ }^{3}$ )

\footnotetext{
${ }^{2}$ We assume in the note that they are twice differentiable.

${ }^{3}$ In an extended dynamic setting (Danthine, Delacroix and Wasmer, 2009), we assume that nature draws which
} 
Given the description of the game, the offering party faces a trade-off between $(i)$ obtaining a more favorable wage and (ii) being turned down by the other party, leaving the offering party with its outside option. Since the payoff from agreement is strictly monotonic in the offered wage, we anticipate a reservation strategies on both sides.

Thus, let us first define a reservation utility level $\nu_{r}=\nu_{r}(w)$ for the worker's idiosyncratic component by

$$
w+\nu_{r}(w)=\mathcal{U}
$$

By definition, $\nu_{r}(w)$ is the utility that makes workers indifferent between accepting and refusing the offer $w$. Thus a wage $w$ ensures that all workers whose private value is above (below) $\nu_{r}(w)$ accept (refuse) the offer. An offer is therefore accepted with probability $G\left(\nu_{r}(w)\right)$. Recognizing that there is no need to $(i)$ offer a wage below one which would be refused for sure by all possible types of workers, or $(i i)$ to offer a wage above one which would be accepted for sure by all types of workers, the trade-off mentioned above implies that the wage $w$ maximizes expected payoff $G\left(\nu_{r}(w)\right) \cdot \mathcal{V}+\left(1-G\left(\nu_{r}(w)\right)\right) \cdot(h+\varepsilon-w)$, or equivalently the expected net surplus

$$
\begin{array}{ll}
\max _{w} & {\left[1-G\left(\nu_{r}(w)\right)\right] \cdot(h+\varepsilon-w-\mathcal{V}),} \\
& \text { s.t. } \nu_{\min } \leq \nu_{r}(w) \leq \nu_{\max } .
\end{array}
$$

The solution to this problem can be an interior or a corner solution, depending on the firm's private value $\varepsilon$.

The interior solution is given by

$$
\frac{g\left(\nu_{r}(w)\right)}{1-G\left(\nu_{r}(w)\right)} \cdot(h+\varepsilon-w-\mathcal{V})=1,
$$

and the associated conditional separation rate is $S(\varepsilon)=G\left(\nu_{r}(w)\right){ }^{4}$

Denote by $H_{G}(\nu)=g(\nu) /(1-G(\nu))$ the hazard rate function associated with the distribution $G$. The first order condition for an interior solution reflects the tensions faced by the firm. By lowering the wage offer, the firm increases its surplus, but also raises $\nu^{r}(w)$ and the chance of a separation. The trade-off is quantified by the hazard rate: at the optimal $w$, the expected marginal cost from reducing the wage - the marginal rejection probability $g\left(\nu_{r}(w)\right)$ times the firm surplus $h+\varepsilon-w-\mathcal{V}$, equals its expected marginal gain - the continuation rate $1-G\left(\nu_{r}(w)\right.$ times the marginal surplus gain (unity). ${ }^{5}$

Assumption 3. $H_{G}$ is non-decreasing.

\footnotetext{
side makes the offer every time a negotiation takes place. It turns out that solving for equilibrium remains simple, as it suffices to solve for the ex-ante expected payoff from negotiating.

${ }^{4}$ The second order condition requires that $g^{\prime}\left(\nu_{r}\right) \frac{1-G\left(\nu_{r}\right)}{g\left(\nu_{r}\right)}+2 g\left(\nu_{r}\right)>0$.

${ }^{5}$ Getting to make an offer may or may not be desirable: the party making the offer has to give up some surplus which is informational rent to the other side. However, this is alleviated by the fact that making the offer affords one side the option to remove all risk of having an offer rejected, if doing so were very costly.
} 
Proposition 1 Under Assumption 3, if an interior solution for a firm wage offer exists: (a) it is unique ; (b) $w(\varepsilon)$ is increasing in $\varepsilon$.

Proof. The interior solution (1) can be expressed as

$$
H_{G}\left(\nu_{r}\right) \cdot\left[h+\varepsilon+\nu_{r}-\mathcal{U}-\mathcal{V}\right]=1,
$$

where the dependence of $\nu_{r}$ on $w$ is implicit. Thus, $h+\varepsilon+\nu_{r}-\mathcal{U}-\mathcal{V}=\left[H_{G}\left(\nu_{r}\right)\right]^{-1}$. The left-hand side is linear in $\nu_{r}$ and the right-hand side is decreasing or constant, so that there is at most one solution and thus one wage. Also, application of the implicit function theorem shows that $\frac{d \nu_{r}}{d \varepsilon}<0$, thus that $w$ increases in $\varepsilon$.

Assumption 3 is only a sufficient condition, satisfied for a wide range of distributions (uniform, normal, exponential, etc...). The first part of the proposition implies that equation (1) determines a well-defined interior solution. The second part makes intuitive sense: the higher the firm idiosyncratic productivity, the more costly it is to incur a breakdown and thus high- $\varepsilon$ firms offer high wages to reduce the chance of a separation.

We also have the possibility of corner solutions. The firm's problem yields a corner at $\nu_{r}=\nu_{\max }$ when there is not enough surplus in the match to possibly make an attractive offer even to a worker with the highest private utility, i.e. when $h+\varepsilon+\nu_{\max }-\mathcal{U}-\mathcal{V} \leq 0$. We make the parametrical assumption to rule out that trivial case.

The more interesting corner is the case where $\nu_{r}(w)=\nu_{\min }$. That happens when a firm wants to ensure that all workers accept the offer, because it itself has a high value of $\varepsilon{ }^{6}$ The corner solution is $\bar{w}=\mathcal{U}-\nu_{\min }$ and the associated conditional separation rate is $S(\varepsilon)=0$. It can be readily verified that the corner solution prevails when $H_{G}\left(\nu_{\min }\right)\left[h+\varepsilon+\nu_{\min }-\mathcal{U}-\mathcal{V}\right] \geq 1$.

In fact, define the threshold $\widehat{\varepsilon}$ as

$$
H_{G}\left(\nu_{\min }\right) \cdot\left[h+\widehat{\varepsilon}+\nu_{\min }-\mathcal{U}-\mathcal{V}\right]=1
$$

If $\widehat{\varepsilon} \leq \varepsilon_{\min }$ then the corner solution always prevails, while if $\widehat{\varepsilon} \geq \varepsilon_{\max }$ the interior solution always prevails. Otherwise, $\widehat{\varepsilon}$ represents a threshold above (below) which the interior (corner) solution prevails. Given the uniqueness of the interior solution, we have a simple partition of the support of the distribution $F$ into two regions, separated by a unique $\widehat{\varepsilon}$ defined by the value of $\varepsilon$ for which the interior and corner solutions coincide [see eqs. (2)-(3)]. Using this threshold property, the wage and separation rates can be simply described as

$$
\left\{\begin{array}{l}
\text { If } \varepsilon<\widehat{\varepsilon}, \quad w(\varepsilon) \text { given by }(1) \text { and } S(\varepsilon)=G\left(\nu_{r}(w(\varepsilon))\right), \\
\text { If } \varepsilon \geq \widehat{\varepsilon}, \quad w(\varepsilon)=\mathcal{U}-\nu_{\min } \text { and } S(\varepsilon)=0 .
\end{array}\right.
$$

Considering only the case where $\widehat{\varepsilon} \geq \varepsilon_{\min }$ so that negotiations sometimes fail, we find that the

\footnotetext{
${ }^{6}$ This of course could not happen if $\nu_{\min }=-\infty$.
} 
ex-ante turnover rate (prior to drawing $\varepsilon$ ) is ${ }^{7}$

$$
S=\int_{\varepsilon_{\min }}^{\widehat{\varepsilon}} G\left[\nu_{r}(w(\varepsilon))\right] d F(\varepsilon) .
$$

The probability of a separation is fully determined by the productivity threshold $\widehat{\varepsilon}$. Notice that the interpretation is different from the reservation productivity in a traditional full information Mortensen and Pissarides (1994) framework. In MP, the reservation productivity is also sufficient to compute the ex-ante probability of a separation, since it defines the level below which all matches break down. In this setup too, all matches with $\varepsilon \geq \widehat{\varepsilon}$ do survive as firms want to make sure that the match remains in place by offering a non-negative surplus to all types of workers. Yet some matches characterized by $\varepsilon<\widehat{\varepsilon}$ may survive as long as $\nu$ is high enough.

\subsection{The case of exponential distributions}

A particularly simple solution can be obtained when $H_{G}$ is constant, as is the case for exponential distributions, i.e. $G(\nu)=1-e^{-\gamma \nu}$ over $[0,+\infty)$. In that case, $H_{G}(\nu)=\gamma>0$ for all $\nu$. Since the threshold $\widehat{\varepsilon}$ is such that interior and corner solutions coincide, we find using (2)-(3) that $\nu_{r}[w(\varepsilon)]=\widehat{\varepsilon}-\varepsilon$. The negotiating game can be entirely described by the following system

$$
\left\{\begin{array}{l}
\widehat{\varepsilon}=\mathcal{U}+\mathcal{V}-h+\gamma^{-1}, \\
w(\varepsilon)=\mathcal{U}+\min \{0, \varepsilon-\widehat{\varepsilon}\}, \\
S=\int_{\varepsilon_{\min }}^{\widehat{\varepsilon}} G(\widehat{\varepsilon}-\varepsilon) d F(\varepsilon) .
\end{array}\right.
$$

Notice that turnover increases with $\widehat{\varepsilon}$ and thus decreases with $h-(\mathcal{U}+\mathcal{V})$ : the more productive the match is relative to the outside options of workers and firms, the lower turnover is since it is more likely that $\varepsilon$ and $\nu$ are drawn above the no-separation cutoff points.

\subsection{Inefficient separations}

As recognized by Hall and Lazear (1984), asymmetric information setups are plagued by inefficient separations. In this section, we consider the extent of such inefficiency in our framework. We investigate possible remedies and their limitations in section 3.

Separations are efficient when they take place if and only if the total surplus of the match is negative. For sake of generality, we introduce here the notion of "separation waste" and denote it $\phi \geq 0$ (one can think of it as specific capital, which is lost to society as a whole when a separation

\footnotetext{
${ }^{7}$ Notice that worker offers can be analyzed in a similar fashion. When $0<\beta<1$, the ex-ante turnover rate is given by

$$
S=\beta \cdot \int_{\varepsilon_{\min }}^{\widehat{\varepsilon}} G\left[\nu_{r}\left(w_{f}(\varepsilon)\right)\right] d F(\varepsilon)+(1-\beta) \cdot \int_{\nu_{\min }}^{\widehat{\nu}} F\left[\varepsilon_{r}\left(w_{w}(\nu)\right)\right] d G(\nu) .
$$
}


occurs). Thus workers and firms separate efficiently when

$$
h+\varepsilon+\nu-\mathcal{U}-\mathcal{V}<-\phi .
$$

On the other hand, workers and firms separate in equilibrium when $\nu<\nu_{r}(w(\varepsilon))$, or using the wage expression found in section 2.2 , when

$$
h+\varepsilon+\nu-\mathcal{U}-\mathcal{V}<\gamma^{-1}
$$

Thus equilibrium may result in some inefficient separations, when $-\phi<h+\varepsilon+\nu-\mathcal{U}-\mathcal{V}<\gamma^{-1}$. There are two sources of inefficiencies. First, individual firms and workers do not take into account the separation waste $\phi$ which is costly to society as a whole. Second, some inefficient separations are due to asymmetric information. We can see that the lower $\gamma$, the higher the proportion of inefficient separations. Indeed, workers' private information confer informational rent to them. Thinking back in terms of the trade-off faced by firms in making their offers, as shown in section 2.1 , the lower the hazard rate the less risky it is for firms to offer low wages. The hazard rate of the distribution $G$ is equal to $\gamma$ so that a lower value of $\gamma$ implies that firms are relatively more "aggressive" in their wage offers, leading to more separations, possibly when the match has a positive surplus.

\section{The model with separation costs}

Hall and Lazear (1984) investigated several schemes aimed at alleviating these inefficiencies. They mostly focused on wage schemes, but upon a suggestion made by O. Hart also discuss the possibility of severance payment. We follow this line of research and now introduce the possibility of taxing separations. The idea is to make it more costly to reject an offer. As in section 2, we only look at the case of firm offers, but our results can be extended to offers on both sides.

We denote by $\tau^{f}\left(\tau^{w}\right)$ the penalty/subsidy to the firm (worker) when the offer is rejected and do not restrict the sign of either. A separation tax is the case where $\tau^{f}>0$ and $\tau^{w}=0$ (or vice versa), while a severance payment corresponds to the case $\tau^{f}+\tau^{w}=0$. From a social point of view, we consider that separation taxes are redistributed lump-sum.

\subsection{Equilibrium}

We can proceed as in section 2.1 to compute equilibrium. The reservation rule must now take termination costs into account,

$$
w+\nu_{r}(w)=\mathcal{U}-\tau^{w} .
$$

The firm's offer $w$ is then given by:

$$
\begin{aligned}
\max _{w} & {\left[1-G\left(\nu_{r}(w)\right)\right] \cdot\left(h+\varepsilon-w-\mathcal{V}+\tau^{f}\right), } \\
& \text { s.t. } \nu_{r}(w) \geq 0,
\end{aligned}
$$


which leads to the interior solution

$$
w(\varepsilon)=h+\varepsilon-\mathcal{V}-\gamma^{-1}+\tau^{f} .
$$

The corner solution is obtained when no worker rejects the offer, i.e. when $\nu_{r}(w)=0$ or

$$
w=\mathcal{U}-\tau^{w} .
$$

At the new threshold $\widehat{\varepsilon}$ the two solutions coincide, thus

$$
\widehat{\varepsilon}=\mathcal{U}+\mathcal{V}-h+\gamma^{-1}-\tau^{w}-\tau^{f} .
$$

As above, the ex-ante turnover rate $S$ is entirely determined by $\widehat{\varepsilon}$, since $S=\int_{\varepsilon_{\min }}^{\widehat{\varepsilon}} G(\widehat{\varepsilon}-\varepsilon) d F(\varepsilon)$. Turnover is thus reduced by both a tax on the worker and a tax on the firm. We can verify that severance payments have no effect on turnover.

\subsection{Can efficiency be recovered?}

Any penalty being rebated lump-sum, such penalties are welfare-improving by affecting allocations, which in our case is done by ensuring that a separation takes place if and only the total surplus is negative, i.e.

$$
h+\varepsilon+\nu-\mathcal{U}-\mathcal{V}<-\phi .
$$

On the other hand, workers and firms separate in equilibrium when $\nu<\nu_{r}(w(\varepsilon))$, or using the wage expression found in section 3.1 , when

$$
h+\varepsilon+\nu-\mathcal{U}-\mathcal{V}<\gamma^{-1}-\tau^{w}-\tau^{f}
$$

Proposition 2 Suppose that $\phi=0$. When $\tau^{w}+\tau^{f}=\gamma^{-1}$, workers and firms separate efficiently in equilibrium.

Interestingly, the social planner can chose any combination of penalties on the worker and the firm: in a Coasian way, there is an infinite number of efficient combinations of property rights.

Now suppose that separation implies a loss to society, i.e. $\phi>0$. It follows that:

Proposition 3 Suppose that $\phi>0$. When $\tau^{w}+\tau^{f}=\phi+\gamma^{-1}$, workers and firms separate efficiently in equilibrium.

The loss of specific skills induces the social planner to impose a larger penalty on separations.

The remaining question is to determine whether these strong results can be generalized to other distributions. We will find that recovering efficiency fully is only possible with exponential distributions. 
Fix $\varepsilon$. We know that (conditional on $\varepsilon$,) separations taking place in equilibrium are efficient if $\nu<\nu_{\text {eff }}$ where $h+\varepsilon+\nu_{\text {eff }}-\mathcal{U}-\mathcal{V}=-\phi$. The equilibrium (interior) first order condition results in separations whenever $\nu<\nu_{r}$ where $H_{G}\left(\nu_{r}\right)$. $\left[h+\varepsilon+\nu_{r}-\mathcal{U}-\mathcal{V}+\tau^{w}+\tau^{f}\right]=1$. By varying $\tau^{w}+\tau^{f}$, we can affect the value of $\nu_{r}$ in the preceding equation. To recover efficient separations (still for a given $\varepsilon$ ), we need to choose taxes so that $\nu_{r}=\nu_{\text {eff }}$, i.e. $H_{G}(\mathcal{U}+\mathcal{V}-h-\varepsilon-\phi) \cdot\left[\tau^{w}+\tau^{f}-\phi\right]=1$. We can see that there is no hope of recovering efficiency unconditionally for a general distribution, that is with constant taxes, as the social planner would have to impose separation costs contingent on firm's productivity. The only case where we can recover efficiency with constant taxes is when the hazard rate is constant, i.e. for exponential distributions.

Nonetheless, taxes could be used to move closer to efficiency by choosing non-contingent $\tau^{w}+\tau^{f}$ to minimize inefficient separations, now taking into account the distribution of $\varepsilon$.

\section{Conclusion}

In this note, we find that an alternative game of offers generate simple solutions under asymmetric information and can be used in matching literature. Although asymmetric information leads to inefficiencies due to excess turnover, we find that these inefficiencies can be reduced in the presence of separation costs. One conclusion is that with asymmetric information, inefficient separations can be completely removed by adequately choosing separation costs in the case of distributions with a constant hazard rate. Otherwise, inefficiencies can be alleviated by imposing separation costs, but the ability to do so is hampered by the characteristics of the underlying distributions of private values.

Although these results have been derived under the assumption that firms make unilaterally a take-it-or-leave-it offer, results can be extended straightforwardly to offers from both sides. We

conjecture that they could also be extended to a game of offers and counter-offers albeit at some additional complexity cost.

\section{References}

[1] Alessandria, G. and Delacroix, A. (2008) "Trade and the (Dis)Incentive to Reform Labor Markets: The Case of Reform in the European Union." Journal of International Economics 75, p. 151-166.

[2] Alvarez, F. and Veracierto, M. (2001) "Severance Payments in an Economy with Frictions." Journal of Monetary Economics 47 (3), p. 477-498.

[3] Danthine, S., Delacroix, A. and Wasmer, E. (2009) "Job and Workers Flows in Europe and the US: Specific Skills or Employment Protection?" Working Paper. 
[4] Fella, G. (2007), Working Papers 598, "Optimal Severance Pay in a Matching Model" Queen Mary, University of London, Department of Economics

[5] Hall, B. and Lazear, E. (1984) "The Excess Sensitivity of Layoffs and Quits to Demand." Journal of Labor Economics 2 (2), p. 233-257.

[6] Hopenhayn, H. and Rogerson, R. (1993) "Job Turnover and Policy Evaluation: A General Equilibrium Analysis." Journal of Political Economy 101 (5), p. 915-938.

[7] Mortensen, D. and Pissarides, C. (1994) "Job Creation and Job Destruction in the Theory of Unemployment." Review of Economic Studies 61, p. 397-415.

[8] Mortensen, D. and Pissarides, C. (1999) "New Developments in Models of Search in the Labor Market." In: Ashenfelter, O. and Card, D. (eds), Handbook of Labor Economics, Vol. 3, Part 2, p.2567-2627.

[9] Myerson, R. and Satterthwaite, M. (1983) "Efficient Mechanisms for Bilateral Trading." Journal of Economic Theory 29 (2), p. 265-281.

[10] Pissarides, C. (2000) "Equilibrium Unemployment Theory." The MIT Press, 2nd edition.

[11] Shimer, R. (2005) "The Cyclical Behavior of Equilibrium Unemployment and Vacancies." American Economic Review 95 (1), p. 25-49.

[12] Veracierto, M. (2001) "Employment Flows, Capital Mobility and Policy Analysis." International Economic Review 42 (3), p. 571-595.

[13] Wasmer, E. (2006) "Interpreting Europe-US Labor Market Differences: The Specificity of Human Capital Investments." American Economic Review 96 (3), p. 811-831. 